\title{
LEI 11.340/2006: SEU CONTEXTO, CONTEÚDO E APLICAÇÃO.
}

\author{
Carolina Vicente Bisognin* \\ Iásin Schäffer Stahlhöfer** \\ Matheus Castelan Pereira***
}

RESUMO: Entrou em vigor, em setembro de 2006, a lei 11.340/2006, também conhecida como Lei Maria da Penha, em homenagem à senhora que através de suas tragédias pessoais propiciou a elaboração da lei. Tal conjunto normativo é considerado uma forma de discriminação positiva, ao lado de outros marcos regulatórios, como o Estatuto da criança e do Adolescente e Estatuto do Idoso. A nova lei regulamenta os casos de violência doméstica, trazendo diversas mudanças, dentre as quais vale destacar as do processo judicial, do resgate do inquérito policial, do papel participativo da autoridade policial, além das alterações no Código Penal, Código de Processo Penal e Lei de Execução Penal.

PALAVRAS-CHAVE: Violência doméstica. Lei 11.340/2006. Maria da Penha.

ABSTRACT: September, 2006. The law no. 11.340, also known as "Maria da Penha" law is published. It is named after the lady who, through her personal tragedy, inspired the law. This law is considered a kind of "positive discrimination", along with the statutes created to protect the children and the elderly. Maria da Penha law defines domestic violence and inovates in many aspects, mostly when it comes to the law suit, the inquiry, the participative role of policial authorities and alterations in the penal code, penal process code and penal execution law.

KEY-WORDS: Domestic violence. Maria da Penha. Law no. 11.340/2006.

*Acadêmica do $4^{\circ}$ semestre do Curso de Direito da Universidade Federal de Santa Maria. Email: carolinavbisognin@yahoo.com.br

**A Acadêmico do $4^{\circ}$ semestre do Curso de Direito da Universidade Federal de Santa Maria. Email: iasindm @ gmail.com

Acadêmico do $4^{\circ}$ semestre do Curso de Direito da Universidade Federal de Santa Maria. Email: matheus.castelan@ gmail.com

\section{INTRODUÇÃO}

Frente a uma sociedade que busca, a cada dia que passa, a ampliação de seus direitos, a positivação de condutas morais ditas recomendáveis e a reprovação das inadequadas, a Lei n 11.340 de 07 de agosto de 2006, vulgo Maria da Penha, se integra a outras normas, tais como o Estatuto da Criança e do Adolescente e o Estatuto do Idoso, nas que se classificam como "direitos das minorias" ou discriminação positiva.

Devido ao pioneirismo trazido por esta lei, que mescla matéria patrimonial, familiar, processual e penal, ela constitui um desafio ao magistrado que se depara com o caso concreto, bem como todos os institutos que ela abrange.

A nova lei, em seu texto, pretende criar "mecanismos para coibir a violência doméstica e familiar contra a mulher"1. Entre seus maiores méritos está o de arrolar, em seu Capítulo II, outras formas de violência contra a mulher, além da física, quais sejam,

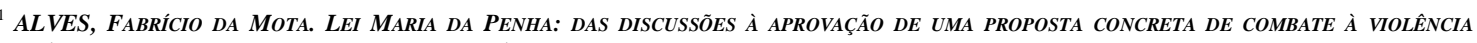
DOMÉSTICA E FAMILIAR CONTRA A MULHER. DISPONÍVEL EM <HTTP://JUS2.UOL.COM.BR/DOUTRINA/TEXTO.ASP?ID=8764>. ACESSO EM 16/06/2007.
} 
a moral, a psicológica, a sexual e a patrimonial. Vê-se nisso uma abertura da mentalidade do legislador, que compreende, finalmente, que a violência que merece ser punida não é apenas aquela aferível mediante exame de corpo de delito. Por vezes, os outros tipos de violência podem trazer consequiências tão ou mais gravosas quanto a violência física.

Outra previsão da Lei n ${ }^{\circ}$ 11.340/2006 é a criação de uma ação conjunta entre os diferentes órgãos do Poder Judiciário, afim de oferecer à mulher em situação de violência doméstica e familiar um aparato institucional adequado às necessidades da vítima. Entre as medidas mais importantes, está a criação de juizados especiais para a apuração e julgamento dos crimes domésticos, com a conseqüente retirada da competência dos Juizados Especiais Criminais para tal.

Nosso escopo é, pois, esclarecer os aspectos normativos e sociais da supracitada lei e facilitar a compreensão desta, haja vista o pouco tempo de vigência desta regulamentação e, portanto, a superficialidade dos estudos acerca dela, pensamos que nosso artigo vem a acrescentar à comunidade científica jurídica.

\section{DA LEI: HISTÓRICO E PRINCIPAIS MEDIDAS PREVISTAS}

No mês de agosto do ano de 2006 foi sancionada a Lei $\mathrm{n}^{\circ}$ 11.340, também intitulada Lei Maria da Penha. A referida lei é fruto de um projeto enviado pela ministra da Secretaria Especial de Política para as Mulheres, Nilcéia Freire, ao Congresso Nacional, no ano de 2004 e recebe este nome em homenagem a farmacêutica Maria da Penha Maia Fernandes.

Maria da Penha tornou-se figura emblemática na luta contra a violência doméstica no Brasil após ter sido vítima do marido, Marco Antônio Heredia Viveiros, que, em 1983, desferiu-lhe tiros enquanto a mesma dormia. Não satisfeito, atentou contra a vida de sua esposa duas semanas após esta regressar do hospital em virtude da agressão anterior: tentou eletrocutá-la enquanto a esposa tomava banho. Como resultado destas e das demais agressões sofridas durante a constância do matrimônio, Maria da Penha apresenta hoje um quadro de paraplegia irreversível, entre outros traumas físicos e psicológicos.

Para que seu ex-marido fosse condenado, Maria da Penha enfrentou um embate judicial cuja duração que em muito excedeu o prazo razoável garantido pela Carta Magna Brasileira. Em vista disso, no ano de 1998, o CEJIL Brasil (Centro para a Justiça e o Direito Internacional) e o CLADEM Brasil (Comitê Latino-Americano do Caribe 
para a Defesa dos Direitos da Mulher), juntamente com Maria da Penha, encaminharam à Comissão Interamericana de Direitos Humanos da OEA denúncia contra o Estado brasileiro, acusando-o de tolerar a violência doméstica, ao não tomar medidas efetivas para processar e punir o agressor, além de violar artigos da Convenção Americana de Direitos Humanos, da Declaração Americana dos Direitos e Deveres do Homem e da Convenção de Belém do Pará. ${ }^{2}$

Não obstante sua recusa em se manifestar a respeito do caso, o Estado brasileiro foi considerado, no informe $\mathrm{n}^{\circ} 54 / 2001^{3}$ da Comissão Interamericana de Direitos Humanos, responsável por sua negligência, omissão e tolerância com relação aos casos de violência doméstica. Neste mesmo informe, foram recomendadas algumas medidas que deveriam ser adotadas pelo Estado brasileiro, entre elas: o desfecho do processo criminal contra o agressor; a instauração de processos administrativos a fim de determinar a responsabilidade pelos atrasos injustificados no processo criminal, pagamento de indenização a Maria da Penha, a título de dano moral e patrimonial, por ter sido excedido o prazo razoável de duração do processo e a adoção de políticas destinadas à erradicação da violência doméstica.

A Lei 11.340/2006 foi sancionada em um contexto social conturbado, em que a exploração da figura da mulher dá-se de diversas formas, por vezes velada.

Existe uma grande defasagem entre as garantias constitucionais de igualdade entre mulheres e homens e a situação - atual, de fato - social, econômica, cultural e política das mulheres no país, a qual se amplia no que se refere às mulheres afrodescendentes e indígenas.

No âmbito do Poder Judiciário, por exemplo, temos visto sentenças judiciais ainda aceitarem a tese da "legítima defesa da honra" em casos de homens que agridem suas esposas ou companheiras. Neste sentido:

SP. JÚRI. LEGITIMA DEFESA DA HONRA. VIOLAÇÃO AO ART. 25 DO CÓDIGO PENAL. SÚMULA 07 DO STJ ${ }^{4}$.

Entendemos que estas trazem conseqüências negativas para a sociedade, fortalecendo estigmas e atitudes de cunho discriminatório com relação às mulheres.

\footnotetext{
${ }_{3}^{2}$ Ciranda Internacional de Informação Independente. Disponível em<http://www.ciranda.net/spip/article460.html>. Acesso em 25/06/2007.

Comitê Latino-Americano do Caribe para a Defesa dos Direitos da Mulher - CLADEM. Disponível em <http://www.cladem.org/espanol/nacionales/brasil/viobrasil.asp>. Acesso em: 02/07/2007.

${ }^{4}$ Superior Tribunal de Justiça. Recurso Especial no 203632, Sexta Turma, Superior Tribunal de Justiça, Relator: Ministro Fontes de Alencar, Julgado em 19/04/2001. Disponível em <www.stj.gov.br>. Acesso em 16/06/2006.
} 
A ausência de "honestidade sexual" da mulher nunca constituiu imunidade à fraude que pode ser empregada para fins sexuais, e não é ético deixar sem proteção como forma de "punição" ou "patrulhamento" da liberdade, aquela que se colocou a usar seu erotismo de forma avolumada, com pouco ou nenhum critério. ${ }^{5}$

Ainda no âmbito institucional, é prova da discriminação que as mulheres sofrem o fato de, até a Lei $\mathrm{n}^{\circ} 11.106 / 2005$, os crimes de posse sexual mediante fraude e atentado ao pudor mediante fraude, só se configuravam se praticados contra considerada mulher considerada "honesta" 6 . Assim, legitimava o Estado brasileiro os crimes contra a liberdade sexual de mulheres consideradas "promíscuas", ao não lhes assegurar a tutela jurisdicional.

\section{DO ASPECTO FORMAL DA LEI}

A presente lei foi criada com respaldo legal no artigo $226 \S 8^{\circ}$ da Constituição Federal, que diz: “乌 $8^{\circ} O$ Estado assegurará a assistência à família na pessoa de cada um dos que a integram, criando mecanismos para coibir a violência no âmbito de suas relações". Além disso, tiveram substancial importância na elaboração da lei o Comitê para a Eliminação de Todas as Formas de Discriminação contra a Mulher (CEDAW), a Convenção de Belém do Pará, além de outros tratados internacionais.

Foram duas as preocupações básicas do legislador ao apresentar a lei:

a) retirar do âmbito de incidência da lei 9099/95 (Lei dos Juizados Especiais), os casos de violência contra a mulher, e proibir a aplicação de penas e medidas alternativas, a fim de que a punição seja mais efetiva e satisfaça o animus de vingança da vítima.

b) estabelecer regras procedimentais próprias para a apuração e julgamento de crimes dessa natureza.

$\mathrm{O}$ caput do artigo $3^{\circ}$ da lei, ao reconhecer os direitos à mulher ao expressar que

Serão asseguradas às mulheres as condições para o exercício efetivo dos direitos à vida, à segurança, à saúde, à alimentação, à educação, à cultura, à moradia, ao acesso à justiça, ao esporte, ao lazer, ao trabalho, à cidadania, à liberdade, à dignidade, ao respeito e à convivência familiar e comunitária, ${ }^{7}$

assemelha-se ao caput do artigo 227 da Constituição Federal, que diz

\footnotetext{
${ }_{5}^{5}$ MARCÃO, Renato. Lei $n^{\circ}$ 11.106/2005: novas modificações ao Código Penal Brasileiro. Jus Navigandi, Teresina, ano 9, nº51, 20 abr. 2005. Disponível em: <http://jus2.uol.com.br/doutrina/texto.asp?id=6603〉. Acesso em: 02/07/2007.

${ }^{6}$ CAPEZ, Fernando. Curso de Direito Penal, volume 2: parte especial. $10^{\mathrm{a}}$ edição. São Paulo, Saraiva, 2006

${ }^{7}$ BRASIL. Lei 11.340 de 07 de agosto de 2006. Disponível em <http://www.planalto.gov.br/ccivil/_Ato2004-2006/2006/Lei/L11340.htm>. Acesso em $12 / 06 / 2007$.
} 
É dever da família, da sociedade e do Estado assegurar à criança e ao adolescente, com absoluta prioridade, o direito à vida, à saúde, à alimentação, à educação, ao lazer, à profissionalização, à cultura, à dignidade, ao respeito, à liberdade e à convivência familiar e comunitária, além de colocá-los a salvo de toda forma de negligência, discriminação, exploração, violência, crueldade e opressão, ${ }^{8}$

caracterizando-se, indubitavelmente, uma discriminação positiva ou ação afirmativa, como preferem alguns.

A Constituição Federal veda, já em seu preâmbulo, a presença de práticas preconceituosas ao afirmar que o Estado é: "destinado a assegurar o exercício dos direitos sociais e individuais, a liberdade, a segurança, o bem-estar, o desenvolvimento, a igualdade e a justiça como valores supremos de uma sociedade fraterna, pluralista e sem preconceitos".

Fato é que o legislador tomou esses parâmetros como norte, podendo-se sim, aplicarem-se as ações afirmativas enquanto e a fim de que o Estado Democrático de Direito Brasileiro realmente venha a existir de fato. Ou seja, são admitidas práticas discriminatórias positivas atualmente para que possamos construir e alcançar os objetivos propostos e almejados pela assembléia constituinte nacional.

A lei 11.340/06, em seu artigo $5^{\circ}$, conceitua violência doméstica como: "qualquer ação ou omissão baseada no gênero que lhe cause morte, lesão, sofrimento físico, sexual ou psicológico e dano moral ou patrimonial", no âmbito da unidade doméstica (inciso I), familiar (inciso II) ou qualquer relação íntima de afeto (inciso III), independendo de relações sexuais, como dispõe o Parágrafo único do supracitado artigo.

O desdobramento desse artigo nos permite fazer dois importantes apontamentos:

a) a ampliação do conceito de família, ao propor que família é a comunidade de indivíduos que "são ou se consideram aparentados, unidos por laços naturais, por afinidade ou por vontade expressa” (inciso II).

São raros os conceitos que são mais abrangentes e modernos no Direito Penal do que no Direito Civil, sendo o presente artigo um exemplo disso: é possível fazermos a exegese de que a agressão proveniente de relacionamento homossexual feminino está regulamentado por esta lei, pois é evidente que o casal de mulheres homossexuais se considera aparentados, apresentando vínculo por afinidade e a vontade expressa de estarem unidas, sendo portanto, como define o professor e assessor parlamentar no Senado Federal Fabrício da Mota Alves, um casal homossexual feminino são

${ }^{8}$ BRASIL. Constituição Federal de 1988. Disponível em <http://www.planalto.gov.br/ccivil_03/Constituicao/Constitui\%C3\%A7ao.htm〉. Acesso em $14 / 07 / 2007$. 
cônjuges 'autoconsiderados', porque, perante si mesmos e perante a sociedade, mas à margem da lei, ambas têm um vínculo íntimo sólido, com envolvimento sexual e afetivo tal qual um casal heterossexual. Além disso, mesmo que o Direito não as reconheça como tal, elas o fazem, mediante ato voluntário de manifestação de vontade. ${ }^{9}$

Consideramos inegável e louvável o avanço que se teve com a promulgação da lei no sentido de reconhecimento da união homoafetiva feminina, e lastimável que a masculina não é tratada por esta ou qualquer outra lei.

Nesse sentido vale apresentar a visionária posição de parte do Tribunal de Justiça do Rio Grande do Sul sobre a união homoafetiva, antes mesmo da entrada em vigor da lei Maria da Penha:

UNIAO HOMOSSEXUAL. (...) NAO SE PERMITE MAIS O FARISAISMO DE DESCONHECER A EXISTENCIA DE UNIOES ENTRE PESSOAS DO MESMO SEXO E A PRODUCAO DE EFEITOS JURIDICOS DERIVADOS DESSAS RELACOES HOMOAFETIVAS. EMBORA PERMEADAS DE PRECONCEITOS , SAO REALIDADES QUE O JUDICIARIO NAO PODE IGNORAR, MESMO EM SUA NATURAL ATIVIDADE RETARDATARIA. NELAS REMANESCEM CONSEQUENCIAS SEMELHANTES AS QUE VIGORAM NAS RELACOES DE AFETO, BUSCANDO-SE SEMPRE A APLICACAO DA ANALOGIA E DOS PRINCIPIOS GERAIS DO DIREITO, RELEVADO SEMPRE OS PRINCIPIOS CONSTITUCIONAIS DA DIGNIDADE HUMANA E DA IGUALDADE. $(\ldots)^{10}$

b) A lei também, ao proteger a mulher que tenha tido qualquer relação íntima de afeto, sem necessária coabitação (inciso III do artigo $5^{\circ}$ ), abrange os casais de "ficantes", namorados e noivos.

Já no artigo $7^{\circ}$ da lei, são apresentadas as espécies clássicas de violências: física, psicológica e sexual e inovou ao apresentar as violências patrimonial e moral. A inclusão destas duas outras formas de violência vem a responder à problemática da mulher, que não raro, sofre agressões verbais perante a família e comunidade e apresenta relação de dependência econômica e financeira pelo agressor.

Isso denota o reconhecimento do legislador da importância e relevância de tais violências, pois elas são muitas vezes, tão ou mais prejudiciais que a violência física ${ }^{11}$.

$\mathrm{O}$ artigo $8^{\circ}$ prevê as práticas de prevenção à violência doméstica, merecendo destaque a) a formalização de convênios, capacitação e especialização dos órgãos de atendimento das vítimas; b) o encargo dado à mídia de desconstruir os estereótipos de

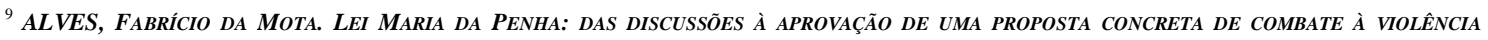
DOMÉSTICA E FAMILIAR CONTRA A MULHER. DISPONÍVEL EM <HTTP://JUS2.UOL.COM.BR/DOUTRINA/TEXTO.ASP?ID=8764>. ACESSO EM 16/06/2007.

${ }^{10}$ Tribunal de Justiça do Rio Grande do Sul. Apelação Cível N ${ }^{\circ}$ 70001388982, Sétima Câmara Cível, Tribunal de Justiça do RS, Relator: José Carlos Teixeira Giorgis, Julgado em 14/03/2001. Disponível em <http://www.tj.rs.gov.br >. Acesso em 16/06/2006.

${ }^{11}$ CAMPOS, Adriana. Abuso emocioanal. Disponível em

<http://www.educare.pt/educare/Opiniao.Artigo.aspx?contentid=E5C7CBCB1AAF4DA2BF803DD09A9A5D51\&channelid=E5C7CBCB1AAF4DA2 BF803DD09A9A5D51\&schemaid=\&opsel=2>. Acesso em 02/07/2006.
} 
gênero e a promover os valores positivos da família e da mulher; c) além da diluição da responsabilidade da prevenção ao Poder Judiciário, Ministério Público e Defensoria Pública através de uma ação operacional integrativa.

Já o art. $9^{\circ}$ trata da "assistência à mulher em situação de violência doméstica e familiar", concedendo a ela assistência social, médica e proteção. O parágrafo $1^{\circ}$ disciplina o cadastro da vítima em programas governamentais de assistência. Contudo, é o parágrafo $2^{\circ}$ que traz uma importante inovação, qual seja uma nova justificativa de remoção da funcionária pública vítima de violência doméstica e a manutenção do vínculo empregatício por 6 meses entre empregada e empregador particular. Há nisso, uma preocupação elogiável com o bem estar da vítima, entretanto, é mais um fator de insegurança ao empregador particular, que já é receoso ao admitir empregados mulheres devido ao risco de gravidez.

$\mathrm{O}$ artigo 10 estabelece que a assistência policial pode ser preventiva, ou seja, quando a conduta criminosa estiver na iminência de ocorrer ou repressiva, quando a prática criminosa já ocorreu.

O artigo 11 trata das providências da autoridade policial, que entre outras, deve garantir a proteção da vítima, informar o Ministério Público e o Poder Judiciário, encaminhar a vítima ao hospital ou ao Instituto Médico Legal, transportar a vítima e seus dependentes a local seguro, acompanhar a vítima ao seu domicílio caso necessite de algum pertence, além de informá-la de seus direitos contidos na lei 11.340/2006.

De todas as providências elencadas pela lei, depreende-se que o legislador traz a autoridade policial para mais perto da população, ou seja, há a intenção de que haja uma autoridade policial mais participativa. Isso para que a vítima se sinta efetivamente protegida e possa manter a denúncia, ao contrário do que corriqueiramente ocorria, pois as vítimas ou retiravam a queixa (pois tinham de voltar ao convívio com o agressor) ou simplesmente não apareciam nas audiências do JECrim, fazendo com que o processo fosse arquivado, conforme relato da Delegada Débora Dias, Delegada da Delegacia da Mulher de Santa Maria.

$\mathrm{O}$ artigo 12 disciplina alguns procedimentos especiais, sem prejuízo daqueles previstos no Código de Processo Penal, quais sejam:

I - ouvir a ofendida, lavrar o boletim de ocorrência e tomar a representação a termo, se apresentada;

II - colher todas as provas que servirem para o esclarecimento do fato e de suas circunstâncias; 
III - remeter, no prazo de 48 (quarenta e oito) horas, expediente apartado ao juiz com o pedido da ofendida, para a concessão de medidas protetivas de urgência; IV - determinar que se proceda ao exame de corpo de delito da ofendida e requisitar outros exames periciais necessários;

$\mathrm{V}$ - ouvir o agressor e as testemunhas;

VI - ordenar a identificação do agressor e fazer juntar aos autos sua folha de antecedentes criminais, indicando a existência de mandado de prisão ou registro de outras ocorrências policiais contra ele;

VII - remeter, no prazo legal, os autos do inquérito policial ao juiz e ao Ministério Público. ${ }^{12}$

Merece destaque a volta do Inquérito Policial em detrimento do Termo Circunstanciado aplicado nos casos regulados pela lei 9099/1995. Essa mudança gerou uma série de críticas dos juristas e operadores do Direito em geral, pois tal substituição acarreta a maior morosidade do processo, uma vez que o Inquérito é bem mais extenso que o Termo Circunstanciado.

Possibilita ainda o artigo 12 a utilização de laudos ou prontuários médicos fornecidos por hospitais ou postos de saúde como prova da agressão sofrida pela vítima.

O art. 14 prevê a criação de Juizados de Violência Doméstica e Familiar contra a Mulher, órgão com competência criminal e cível, podendo ser criados pela União e pelos Estados para o processo, julgamento e execução dos crimes decorrentes da prática de violência doméstica e familiar contra a mulher.

O artigo 16 talvez seja o artigo que contenha mais divergências deste novo diploma legal ao prever que

nas ações penais públicas condicionadas à representação da ofendida de que trata esta Lei, só será admitida a renúncia à representação perante o juiz, em audiência especialmente designada com tal finalidade, antes do recebimento da denúncia e ouvido o Ministério Público. ${ }^{13}$

Poderíamos fazer a exegese de que até o oferecimento da denúncia, a Autoridade Policial e o Ministério Público agiriam de ofício, independente da vontade da vítima, uma vez que esta só poderia desistir da denúncia perante o juiz em audiência específica, mesmo em casos de ação penal pública condicionada à representação. Ter-se-ia, conforme o Delegado Eduardo Luiz Santos Cabette, "uma derrogação tácita dos artigos $5^{\circ}, \S 4^{\mathrm{o}}$ e 24 , ambos do Código de Processo Penal" ${ }^{14}$. Dessa forma, o prazo decadencial

\footnotetext{
${ }^{12}$ BRASIL. Lei 11.340 de 07 de agosto de 2006. Disponível em <http://www.planalto.gov.br/ccivil/_Ato2004-2006/2006/Lei/L11340.htm>. Acesso em $12 / 06 / 2007$

${ }^{13}$ BRASIL. Lei 11.340 de 07 de agosto de 2006. Disponível em <http://www.planalto.gov.br/ccivil/_Ato2004-2006/2006/Lei/L11340.htm>. Acesso em $12 / 06 / 2007$.

${ }^{14}$ CABETTE, Eduardo Luiz Santos. Anotações críticas sobre a lei de violência doméstica e familiar contra a mulher. Disponível em $<$ http://jus2.uol.com.br/Doutrina/texto.asp?id=8822>. Acesso em 25/06/2007.
} 
(artigo 38, Código de Processo Penal) somente poderia começar a correr a partir da dita audiência.

Ocorrido e noticiado um crime de violência doméstica ou familiar contra a mulher, cuja ação penal seja pública condicionada a representação, independentemente da manifestação da ofendida, seria instaurado o respectivo Inquérito Policial, o qual, relatado e enviado a juízo, seria apresentado ao Ministério Público, que também ofertaria a denúncia de ofício. Dessa maneira, a lei teria fechado as portas ao efetivo exercício pela vítima de seu direito de representação, sendo impensável que pudesse transcorrer o respectivo prazo decadencial. Ofertada a denúncia, deveria o Juiz, antes de deliberar sobre seu recebimento, designar a audiência especial a que se refere o artigo 16 da Lei 11.340/06. Somente nessa audiência a vítima poderia dizer efetivamente se deseja ou não ofertar sua representação. Representando e sendo a denúncia recebida, elidida estaria eventual decadência e nem mesmo poder-se-ia falar em retratação (art. 25, CPP) posterior. Também a "renúncia" estaria obstada por força da dicção do artigo 16 da lei ora comentada que estabelece que tal instituto somente possa operar-se "antes do recebimento da denúncia". Por outro caminho, se houvesse "renúncia" do direito de representação na audiência em estudo, extinta estaria a punibilidade do autor do crime por esse instituto e não pela decadência. $^{15}$

No afã de proteger a vítima, percebemos claramente que o legislador acabou cerceando-lhe os direitos e burocratizando os procedimentos que pretendia agilizar.

No capítulo II estão arroladas as chamadas Medidas Protetivas de Urgência. Estas deverão ser requeridas pelo Ministério Público ou pela ofendida: a autoridade policial tem o prazo de $48 \mathrm{~h}$ para concedê-la. Poderão ser concedidas inaudita altera pars, isto é, sem a observação do contraditório e independentemente de manifestação do Ministério Público. Poderão ser concedidas tantas Medidas Protetivas de Urgência quantas forem necessárias para assegurar a segurança da vítima.

No texto da lei, encontram-se elencadas (de forma não-taxativa) estas medidas. Elas subdividem-se naquelas que obrigam o agressor e naquelas que dizem respeito à ofendida.

A decretação de prisão preventiva dar-se-á de ofício, mediante representação do Ministério Público ou da autoridade policial. A vítima devera ser informada de todos os atos processuais, sendo proibida de entregar ao agressor quaisquer notificações.

Com a Lei Maria da Penha, o Ministério Público assume um novo papel: participará de todas as fases de processamento de crimes de violência doméstica, tanto na esfera cível quanto na criminal.

\footnotetext{
15 CABETTE, Eduardo Luiz Santos. Anotações críticas sobre a lei de violência doméstica e familiar contra a mulher. Disponível em <http://jus2.uol.com.br/Doutrina/texto.asp?id=8822>. Acesso em 25/06/2007.
} 
A proibição da substituição da pena privativa de liberdade pela pena pecuniária bem como pela substituição de pena que implique pagamento isolado de multa não se estende às outras penas restritivas de direitos, como a prestação de serviços à comunidade, por exemplo. Tal assunto é tratado pelo artigo 17 da lei e invade o campo processual penal. Na prática entendemos que o agressor não mais poderá, caso condenado, valer-se do pagamento isolado de cestas básicas à vítima, por exemplo. Caberá a ele, então, cumprir pena primitiva de liberdade, ou se cabível, substituí-la por prestação de serviço à comunidade. Vemos tal medida como importante auxiliar na coibição da prática criminosa, uma vez que o encrudecimento da sanção é um dos fatores determinantes na diminuição da prática da ação delituosa.

$\mathrm{Na}$ ordem jurídica brasileira, o crime de lesões corporais vinha, até a entrada em vigor da Lei dos Juizados Especiais (Lei no 9099/1995) sido processado mediante ação penal pública incondicionada. Com o advento desta lei, a ação penal nos crimes de lesões corporais leves e lesões corporais culposas passou a ser condicionada a representação.

A lei Maria da Penha, entretanto, em seu artigo 41, preceitua que "aos crimes praticados com violência doméstica e familiar contra a mulher, independentemente da pena prevista, não se aplica a Lei $\mathrm{n}^{0}$ 9.099, de 26 de setembro de 1995”. Assim, com a Lei Maria da Penha, a ação penal, em casos de lesões corporais dolosas leves passou a ser, novamente, incondicionada, retirando-se a competência dos Juizados Especiais Criminais.

Entendemos esta medida como benéfica, uma vez que caso o legislador não incluísse os crimes de violência doméstica na competência dos Juizados Especiais Criminais - destinados a aferir crimes de menor potencial ofensivo - denotaria certa conivência ou descaso do legislador com estes crimes.

\section{APLICAÇÃO DA LEI 11.340/2006 E A CONJUNTURA SOCIAL}

É perceptível que após a sanção da Lei 11.340/2006, a situação da mulher e da consciência de seus direitos mudou, no que tange à relação familiar. Atualmente é sabido pela maioria delas que sendo vítimas de agressão doméstica previstas na lei, podem denunciar o agressor e este pode ser, de fato, afastado do domicílio da vítima.

A lei também tem contribuído significativamente no sentido de proporcionar à população a idéia de que o agressor será efetivamente punido, inclusive com prisão privativa de liberdade alcançando 3 anos, caso este venha a ferir a integridade da 
mulher, seja esta física, psicológica, sexual, patrimonial, ou moral, como explicado anteriormente. Acabando com a falsa e repugnante idéia de que violência doméstica se resolve com "flores ou cestas básicas".

Exemplo do fato citado acima, é em Pernambuco, um dos estados brasileiros onde há maior incidência de violência doméstica. Só nos cinco primeiros dias após o sancionamento da lei, foram caracterizados treze casos de flagrante de agressão contra a mulher, enquadrados na Lei Maria da Penha, segundo pesquisa da Folha de Pernambuco, em novembro de 2006.

Outro bom exemplo de que esta lei causou impacto positivo, é no estado do Rio Grande do Sul, em que aumentaram em praticamente $50 \%$ as denúncias por agressão doméstica, nas delegacias especializadas em atendimento às mulheres.

Estes dados não nos revelam que o encrudecimento da legislação tenha acarretado a diminuição dos casos de agressão doméstica, contudo, é fato que está crescendo significativamente o número de denúncias decorridas da incidência da lei, devido aos fatos já mencionados, como maior sentimento de segurança da vítima de que o agressor será punido e que graças à proteção policial este não se voltará contra a vítima novamente.

Em entrevista com M.T. (a vítima preferiu não ter seu nome revelado), ela informou que fora frequentemente agredida pelo então marido dentro de casa. Este estava neste período desempregado, e chegava diariamente embriagado em casa. Agressivo, ele usava a esposa como "cano de descarga" para suas frustrações profissionais. A vítima revela que embora tivesse procurado uma delegacia para dar queixa do marido, acabou não registrando ocorrência, pois além de se sentir intimidada frente aos policiais que lá estavam, percebeu (após conversar com um deles) que o marido dificilmente seria punido por seus atos, frustrando seu ideal de livrar-se das agressões justamente por aqueles aos quais ela fora buscar auxílio e conforto.

M.T. aduz que então, após sancionada a lei 11.340/2006, ela se sentiu encorajada para novamente tentar a denúncia contra o marido. Conseguiu então caracterizar a agressão, através das escoriações e hematomas que apresentava, e pelo relato do filho de 5 anos que ela tinha com o agressor. Atualmente, ele já não mais reside junto à ela e responde processo por lesão corporal.

Infelizmente ainda não se pode afirmar que a lei 11.340/06 obteve êxito total perante sua proposta. Muitos ainda são os empecilhos à que as mulheres garantam seus direitos. 
Segundo a Dra. Débora Dias, a vergonha perante a sociedade, e o medo de se desatrelar do marido, no que tange ao caráter econômico, faz com que grande parte das mulheres agredidas se conformem com o fato de apanhar dos maridos, ou então serem forçadas a manter relações sexuais com eles.

Como nossa sociedade ainda é extremamente machista, as mulheres sentem-se encabuladas em denunciar o marido, como se o fazendo, elas estivessem sendo ingratas para com quem as sustenta, diz a delegada.

É evidente que ainda está presente em nossa sociedade (embora reduzido se comparado a poucas décadas atrás) a visão paternalista, onde o homem deve ser o centro do sustento da casa, a autoridade domiciliar, e aos outros membros da casa resta apenas consentir com suas decisões e atitudes. Isto faz com que a mulher se abata por um sentimento conformista frente à agressão sofrida, já que em sua percepção é submissa.

Alerta ainda a delegada Débora que este quadro nos leva a pensar, equivocadamente, que agressão familiar ocorre somente nas camadas inferiores da sociedade, já que, se munida de condição financeira favorável, a mulher então procuraria um advogado para se separar do marido, ou então usar de outra forma para cessar com as agressões. Porém ocorre de a vítima se sentir intimidada pela sociedade, nos casos em que não querendo que seja percebido que o seu casamento passa por crise, e que ela passou da condição de esposa à vítima. Este seria então, para as camadas de maior nível de renda, o motivo para o silêncio feminino.

Porém segundo a delegada, o fato que mais impossibilita as mulheres de denunciarem seus cônjuges por agressão é caracterizado nas camadas sociais mais baixas. Como geralmente as famílias não são composta meramente de marido e mulher, mas também de filhos, elas aceitam sua "sina" em detrimento do sustento da sua prole. Geralmente, quando a mulher não tem filhos, ela denuncia, pois não há nada que a impeça de fazê-lo, podendo muito bem ela deixar a casa onde residia com o agressor (que é o que, segundo a delegada, geralmente acontece).

\section{CONSIDERAÇÕES FINAIS}

A lei 11.340/2006 indubitavelmente traz inovações, não só protetivas às mulheres, mas também a ampliação do conceito civil de família, abrangendo a união homoafetiva feminina, a aproximação da autoridade policial à vítima de violência 
doméstica, a ampliação dos tipos clássicos de violência, ao incluir a patrimonial e a moral, além de toda rede protetiva dada à mulher.

Porém parece retroceder em alguns aspectos, como no caso da restauração do inquérito policial e da impossibilidade da vítima renunciar à denúncia antes da propositura da ação, levando, inevitavelmente, ao acréscimo da morosidade do Poder Judiciário.

De qualquer forma, é louvável a iniciativa protetiva do legislador frente ao triste quadro fático atual da mulher brasileira. Oxalá possamos ver a lei aplicada em toda sua extensão.

\section{REFERÊNCIAS BIBLIOGRÁFICAS}

ALVES, FABRício da Mota. LEI MARIA DA PENHA: DAS DISCUSSÕES À APROVAÇ̃̃o dE UMA PROPOSTA CONCRETA DE COMBATE À VIOLÊNCIA DOMÉSTICA E FAMILIAR CONTRA A MULHER. DISPONÍVEL EM <HTTP://JUS2.UOL.COM.BR/DOUTRINA/TEXTO.ASP?ID=8764>. ACESSO EM 16/06/2007.

ALVES, FABRício dA MOTA. LEI MARIA DA PENHA: DAS DISCUSSÕES À APROVAÇÃo DE UMA PROPOSTA CONCRETA DE COMBATE À VIOLÊNCIA DOMÉSTICA E FAMILIAR CONTRA A MULHER II. DISPONÍVEL EM <HTTP://JUS2.UOL.COM.BR/DOUTRINA/TEXTO.ASP?ID=8764\&P=2>. ACESSO EM 16/06/2007.

BRASIL. Constituição Federal de 1988. Disponível em <http://www.planalto.gov.br/ccivil_03/Constituicao/Constitui\%C3\%A7ao.htm>.

Acesso em 14/07/2007.

BRASIL. Lei 11.340 de 07 de agosto de 2006. Disponível em <http://www.planalto.gov.br/ccivil/_Ato2004-2006/2006/Lei/L11340.htm>. Acesso em 12/06/2007.

CABETTE, Eduardo Luiz Santos. Anotações críticas sobre a lei de violência doméstica e familiar contra a mulher. Disponível em $<$ http://jus2.uol.com.br/Doutrina/texto.asp?id=8822>. Acesso em 25/06/2007.

CAMPOS, Adriana. Abuso Emocional. Disponível em <http://www.educare.pt/educare/Opiniao.Artigo.aspx?contentid=E5C7CBCB1AAF4D A2BF803DD09A9A5D51\&channelid=E5C7CBCB1AAF4DA2BF803DD09A9A5D51 \&schemaid=\&opsel=2>. Acesso em 02/07/2007.

CAPEZ, Fernando. Curso de Direito Penal, volume 2: parte especial. $10^{\mathrm{a}}$ edição. São Paulo, Saraiva, 2006.

Ciranda Internacional de Informação Independente. Disponível em <http://www.ciranda.net/spip/article460.html>. Acesso em 06/06/2007.

Comitê Latino-Americano do Caribe para a Defesa dos Direitos da Mulher - CLADEM. Disponível em <http://www.cladem.org/espanol/nacionales/brasil/viobrasil.asp>. Acesso em: 02/07/2007.

GERBER, Daniel. Direito penal do inimigo: Jackobs, nazismo e a velha estória de sempre. Disponível em <http://jus2.uol.com.br/doutrina/texto.asp?id=7340>. Acesso em 08/07/2007. 
MARCÃO, Renato. Lei $\mathbf{n}^{\mathbf{0}}$ 11.106/2005: novas modificações ao Código Penal Brasileiro. Jus Navigandi, Teresina, ano 9, n651, 20 abr. 2005. Disponível em: <http://jus2.uol.com.br/doutrina/texto.asp?id=6603>. Acesso em: 02/07/2007.

Organização dos Estados Americanos (OEA). Comissão Interamericana de Direitos Humanos. Disponível em <http://www.cidh.oas.org/annualrep/2000port/12051.htm>. Acesso em 15/07/2007.

ROBALDO, José Carlos de Oliveira. Lei Maria da Penha: Alguns aspectos relevantes. Disponível em: <http://www.lfg.com.br/public_html/article.php?story=20061024124609147\&mode=pri nt>. Acesso em 17/06/2007.

Instituto Patrícia Galvão - Portal da Violência contra a Mulher. Disponível em: <http://www.patriciagalvao.org.br>

Superior Tribunal de Justiça. Recurso Especial no 203632, Sexta Turma, Superior Tribunal de Justiça, Relator: Ministro Fontes de Alencar, Julgado em 19/04/2001. Disponível em <www.stj.gov.br>. Acesso em 16/06/2006.

TRINDADE, Fernando. A Constitucionalidade da Discriminação Positiva. Disponível em <http://www.senado.gov.br/conleg/artigos/direito/AConstitucionalidadedaDiscriminaca o.pdf>. Acesso em 08/07/2007.

Tribunal de Justiça do Rio Grande do Sul. Apelação Cível No 70001388982, Sétima Câmara Cível, Tribunal de Justiça do RS, Relator: José Carlos Teixeira Giorgis, Julgado em 14/03/2001. Disponível em <http://www.tj.rs.gov.br >. Acesso em 16/06/2006. 
